\title{
Incorporation of either molybdenum or tungsten into formate dehydrogenase from Desulfovibrio alaskensis NCIMB 13491; EPR assignment of the proximal iron-sulfur cluster to the pterin cofactor in formate dehydrogenases from sulfate-reducing bacteria
}

Received: 3 June 2003 / Accepted: 24 October 2003/Published online: 11 December 2003

(c) SBIC 2003

\begin{abstract}
We report the characterization of the molecular properties and EPR studies of a new formate dehydrogenase $(\mathrm{FDH})$ from the sulfate-reducing organism Desulfovibrio alaskensis NCIMB 13491. FDHs are enzymes that catalyze the two-electron oxidation of formate to carbon dioxide in several aerobic and anaerobic organisms. D. alaskensis FDH is a heterodimeric protein with a molecular weight of $126 \pm 2 \mathrm{kDa}$ composed of two subunits, $\alpha=93 \pm 3 \mathrm{kDa}$ and $\beta=32 \pm 2 \mathrm{kDa}$, which contains $6 \pm 1 \mathrm{Fe} /$ molecule, $0.4 \pm 0.1 \mathrm{Mo} /$ molecule, $0.3 \pm 0.1 \mathrm{~W} /$ molecule, and $1.3 \pm 0.1$ guanine monophosphate nucleotides. The UV-vis absorption spectrum of $D$. alaskensis FDH is typical of an iron-sulfur protein with a broad band around $400 \mathrm{~nm}$. Variable-temperature EPR studies performed on reduced samples of $D$. alaskensis FDH showed the presence of signals
\end{abstract}

C. D. Brondino $\cdot$ J. Caldeira $\cdot$ M. J. Almendra

J. J. G. Moura · I. Moura ( $\triangle)$

REQUIMTE, Departamento de Química,

Centro de Química Fisica e Biotecnologia,

Faculdade de Ciências e Tecnologia,

Universidade Nova de Lisboa, 2829-516 Caparica, Portugal

E-mail: isa@dq.fct.unl.pt

Tel.: + 351-21-2948381

Fax: + 351-21-2948550

C. D. Brondino · M. C. G. Passeggi

Departamento de Física,

Facultad de Bioquímica y Ciencias Biologicas,

Universidad Nacional del Litoral, 3000 Santa Fe, Argentina

M. C. G. Passeggi

Instituto de Desarrollo Tecnologico (UNL-CONICET),

3000 Santa Fe, Argentina

M. J. Feio

School of Pharmacy and Biomedical Sciences,

University of Portsmouth, St. Michael's Building,

White Swan Road, Portsmouth, PO1 2DT UK

Present address: M. J. Feio

Instituto de Bioquímica Vegetal y Fotosíntesis, Centro de Investigaciones Científicas Isla de la Cartuja,

Av. Américo Vespucio s/n, 41092 Seville, Spain associated with the different paramagnetic centers of D. alaskensis FDH. Three rhombic signals having $g$-values and relaxation behavior characteristic of $[4 \mathrm{Fe}-$ $4 \mathrm{~S}$ ] clusters were observed in the 5-40 K temperature range. Two EPR signals with all the $g$-values less than two, which accounted for less than 0.1 spin/protein, typical of mononuclear $\mathrm{Mo}(\mathrm{V})$ and $\mathrm{W}(\mathrm{V})$, respectively, were observed. The signal associated with the $\mathrm{W}(\mathrm{V})$ ion has a larger deviation from the free electron $g$-value, as expected for tungsten in a $\mathrm{d}^{1}$ configuration, albeit with an unusual relaxation behavior. The EPR parameters of the $\mathrm{Mo}(\mathrm{V})$ signal are within the range of values typically found for the slow-type signal observed in several Mo-containing proteins belonging to the xanthine oxidase family of enzymes. $\mathrm{Mo}(\mathrm{V})$ resonances are split at temperatures below $50 \mathrm{~K}$ by magnetic coupling with one of the $\mathrm{Fe} / \mathrm{S}$ clusters. The analysis of the inter-center magnetic interaction allowed us to assign the EPR-distinguishable iron-sulfur clusters with those seen in the crystal structure of a homologous enzyme.

Keywords Electron paramagnetic resonance · Formate dehydrogenase - Magnetic interactions . Molybdenum-containing enzymes

Tungsten-containing enzymes

Abbreviations $A O R$ aldehyde oxidoreductase $\cdot F D H$ formate dehydrogenase $N A P$ periplasmic nitrate reductase $\cdot S R B$ sulfate-reducing bacteria

\section{Introduction}

Molybdenum- and tungsten-containing enzymes are a wide group of proteins present in several living systems that participate in hydroxylation and oxo-transfer reactions. With the exception of nitrogenase, the metal ion is associated with either one or two pterin derivatives 
to form a metallic cofactor (hereafter called pterin cofactor) $[1,2,3]$. Most of the proteins studied so far contain molybdenum in their active sites, though in the last two years the number of proteins having tungsten has considerably increased. Tungstoproteins are usually found in thermophilic organisms that grow in extreme environments. However, the number of reports of tungstoproteins from other sources has considerably increased in recent years $[4,5]$.

We have reported the characterization of two formate dehydrogenases (FDHs) from the sulfate-reducing bacteria (SRB) Desulfovibrio desulfuricans ATCC 27774 [6, 7] and Desulfovibrio gigas $[4,8,9]$ that belong to the DMSO reductase family (DMSO $=$ dimethyl sulfoxide). FDHs catalyze the two-electron oxidation of formate to carbon dioxide. D. desulfuricans FDH contains molybdenum at the pterin cofactor whereas the one from $D$. gigas contains tungsten. $D$. desulfuricans FDH presents a heterotrimeric structure $(\alpha=88 \mathrm{kDa}, \beta=29 \mathrm{kDa}$, and $\gamma=16 \mathrm{kDa}$ ), whereas D. gigas FDH is heterodimeric $(\alpha=92 \mathrm{kDa}$ and $\beta=29 \mathrm{kDa})$. The crystal structure of $D$. gigas FDH revealed that besides the pterin cofactor, four iron-sulfur clusters of the $[4 \mathrm{Fe}-4 \mathrm{~S}]$ type are present (Fe/S I, II, III, and IV), one of them being $14.4 \AA$ from the pterin cofactor (proximal center). The larger subunit of this enzyme contains the pterin cofactor and the proximal iron-sulfur cluster. The smaller subunit contains the remaining three iron-sulfur clusters. The four iron-sulfur centers are along a "ziz-zag" line separated from each other by $\sim 10 \AA$. The larger subunit of the $D$. gigas FDH is homologous to the periplasmic nitrate reductase (NAP) from D. desulfuricans [10] and the FDH-H from Escherichia coli [11]. Furthermore, all the evidence obtained up to the present suggests that $D$. gigas FDH presents a high homology with the recently reported W-containing FDH-2 from $S$. fumaroxidans [5] and with the two larger subunits present in $D$. desulfuricans $\mathrm{FDH}[6]$.

The presence of iron-sulfur clusters of the type [4Fe-4S] in both $D$. gigas and $D$. desulfuricans has been shown by EPR and Mössbauer spectroscopies [4, 6, 8]. EPR studies performed on both enzymes in the dithionite-reduced state showed two types of EPR signals. The Fe/S I EPR signal appears below $70 \mathrm{~K}$ and shows no broadening below $40 \mathrm{~K}$. The other one, which is identified as Fe/S II, appears below $30 \mathrm{~K}$ and shows much broader resonance lines. It was suggested that the remaining iron-sulfur centers present both EPR and Mössbauer properties similar to $\mathrm{Fe} / \mathrm{S}$ I and II, but additional work should be performed to confirm this hypothesis [8]. The EPR properties of the $\mathrm{Fe} / \mathrm{S}$ I center evaluated in FDHs from SRB are similar to those observed in NAP [12] and E. coli FDH [13]. On this basis, this center should be the center present in the larger subunit of these enzymes, but no spectroscopic evidence has been shown so far.

We report herein the characterization of the molecular properties and EPR studies performed on a FDH obtained from $D$. alaskensis NCIMB 13491, a SRB involved in metal corrosion [14]. D. alaskensis FDH is closely related to the $\mathrm{W}$-containing $D$. gigas FDH. However, metal quantification and EPR studies indicate that the enzyme is a mixture of two forms, each containing either a mononuclear Mo site or a mononuclear W site. Furthermore, the Mo site is magnetically coupled to one of the iron-sulfur clusters. The results obtained for this protein are discussed in comparison with other $\mathrm{W}$ - and Mo-containing proteins. 4

\section{Materials and methods}

Growth conditions, protein purification, and enzymatic activity

D. alaskensis NCIMB 13491 was grown at $37^{\circ} \mathrm{C}$ in Postgate C medium [15] under anaerobic conditions in the Unite de Fermentation at LBC-CNRS in Marseille, France, and cells were harvested at the logarithmic/early stationary phase of bacterial growth. In general, the growth media used for biomass production of SRB intended for protein isolation includes a metal supplement. In this experiment a more basic medium was used for the cell growth. It contained a large amount of iron $(140 \mu \mathrm{M})$ but only trace amounts of all other metals (added mainly as contaminants by the various medium components, in particular yeast extract). This medium was chosen because it mimics better the natural growth conditions experienced by SRB in their natural habitats, where nutrient sources are often scarce [14].

All extraction and purification procedures were performed aerobically at $4{ }^{\circ} \mathrm{C}$ and $\mathrm{pH} 7.6$ with reagent grade or higher. The pellet of cells ( $265 \mathrm{~g}$ wet weight) was suspended in $10 \mathrm{mM}$ Tris- $\mathrm{HCl}$ buffer. Deoxyribonuclease and ribonuclease were added to lower the viscosity. A cell-free extract was obtained by centrifugation of the cellular suspension at $5000 \times g$ for $40 \mathrm{~min}$ and the supernatant $(300 \mathrm{~mL})$, containing mostly the periplasmic proteins, was collected. To remove any membrane contamination, the supernatant was spun at $180,000 \times g$ for $1 \mathrm{~h}$. The periplasmic fraction $(300 \mathrm{~mL})$, initially with 381 total units (U), was loaded onto an anion exchange column (DEAE-52 cellulose, Whatman $6 \times 32.5 \mathrm{~cm}$ ) equilibrated with $10 \mathrm{mM}$ Tris-HCl. The column was eluted with a linear gradient $(0.01-0.60 \mathrm{M})$ of the same buffer with a total volume of $2 \mathrm{~L}$. The enzyme, with $122 \mathrm{U}$ and a specific activity of $0.13 \mathrm{U} \mathrm{mg}^{-1}$ and a yield of $32 \%$, was found in the fraction eluted at $\sim 200 \mathrm{mM}$ Tris- $\mathrm{HCl}$. This fraction was then dialyzed against Millipore water and applied to an anionic exchange column (Source 15, Pharmacia $2.7 \times 20 \mathrm{~cm}$ ). The proteins were eluted using a Tris- $\mathrm{HCl}$ buffer gradient $(0.01-0.50 \mathrm{M})$; the fraction that mainly contained FDH activity was collected at $\sim 200 \mathrm{mM}$ ionic strength and its specific activity was $1.63 \mathrm{U} \mathrm{mg}^{-1}$ ( $82 \mathrm{U}$ and a yield of $22 \%$ ). The ionic strength of this fraction was decreased adding Millipore water. The next and final step was performed on a Source-Q column, using a Tris- $\mathrm{HCl}$ buffer gradient $(0.01-0.50 \mathrm{M})$. The enzyme was found to be pure with $38.1 \mathrm{U}$, a specific activity $=3.51 \mathrm{U} \mathrm{mg}^{-1}$ and a final yield of $10 \%$.

The FDH activity assay was performed with formate as substrate and benzyl viologen as electron acceptor. A standard optical assay of FDH was performed at room temperature under an argon atmosphere, by monitoring the benzyl viologen reduction at $555 \mathrm{~nm}\left(\epsilon=12 \mathrm{mM}^{-1} \mathrm{~cm}^{-1}\right)$, as described elsewhere [6]. One unit of FDH activity was defined as the amount of enzyme catalyzing the reduction of $2 \mu \mathrm{mol}$ of benzyl viologen $/ \mathrm{min}$.

\section{Molecular mass determination}

Molecular mass of the purified protein was determined by gel filtration chromatography using a Superdex 200 column 10/30 HR (Pharmacia) connected to an HPLC system (Jasco PU-980). The elution buffer was $100 \mathrm{mM}$ Tris- $\mathrm{HCl}(\mathrm{pH}$ 7.6) containing $150 \mathrm{mM}$ $\mathrm{NaCl}$ and the proteins used as size markers were: ribonuclease $\mathrm{A}$ $(13.7 \mathrm{kDa})$, chymotrypsinogen A $(25 \mathrm{kDa})$, ovalbumin $(43 \mathrm{kDa})$, bovine serum albumin $(67 \mathrm{kDa})$, aldolase $(158 \mathrm{kDa})$, catalase 
(232 kDa), and ferritin (440 kDa), from Pharmacia Biotech. Subunit composition was determined by SDS-PAGE at $12.5 \%$ using the Pharmacia low molecular mass kit as standard for calibration. Gels were stained with Coomassie brilliant blue G-250 (Merck).

Protein and metals quantification

Protein concentration was determined by the Lowry method using bovine serum albumin as standard [16]. The quantification of tungsten, molybdenum, and iron was performed by inductively coupled plasma emission analysis.

Analysis of pterin nucleotides

Nucleotides were extracted from D. alaskensis FDH by a previously published procedure $[17,18]$. Cofactor extraction was performed with sulfuric acid $(3 \% \mathrm{v} / \mathrm{v})$ for $10 \mathrm{~min}$ at $95{ }^{\circ} \mathrm{C}$, with subsequent centrifugation in a microcentrifuge for $5 \mathrm{~min}$ at $10,000 \mathrm{rpm}$. Chromatography analysis was carried out using a Merck L-7100 HPLC equipped with a L-7100 UV detector and D7000 computer interface. Hydrolyzed nucleotide peak areas were quantified at $254 \mathrm{~nm}$. Ammonium acetate (HPLC grade) $(50 \mathrm{mM}$, $\mathrm{pH}$ 6.8) was used as eluent at a flow rate of $1 \mathrm{~mL} \mathrm{~min}^{-1}$, using a Merck LiChorspher $100(250 \times 4)$ RP-18e, $4 \mu \mathrm{m}$ column. Quantitative determinations were performed with an injection loop volume of $50 \mu \mathrm{L}$ from extracted nucleotides and fresh solutions of mononucleotides (Sigma) submitted to identical acid/heating treatment.

Spectroscopic methods

The UV-visible optical spectrum of the as-isolated enzyme was recorded on a Shimadzu UV-2101 PC split-beam spectrophotometer using $1 \mathrm{~cm}$ quartz cells. Variable-temperature EPR measurements at X-band were performed on a Bruker EMX spectrometer equipped with a dual-mode cavity (model ER 4116DM) and an Oxford Instruments continuous flow cryostat. Spin quantification was performed under non-saturating conditions using $\mathrm{Cu}$-EDTA as standard. EPR spectra were simulated using either WINEPR Simfonia v.1.25 from Bruker Instruments, or a home-made program described below. For the spectra showing overlapping EPR signals, the signals associated with each center were separately simulated, normalized by double integration, and then added altogether in different proportions until best agreement was obtained between experimental and simulated data. The temperature variation of the spectra associated with $\mathrm{Mo}(\mathrm{V})$ species were simulated using a home-made program based on the formalism WBR (Wangenesst, Bloch, and Redfield) for a dimer of two $S=1 / 2$ ions [19]. This program solves the components of the density matrix required to calculate the imaginary part of $\chi^{\prime \prime}(\omega)$ (dynamic susceptibility) and takes the elements of the relaxation matrix as semi-empirical parameters $\left(T_{1}\right.$ and $\left.T_{2}\right)$ for each center [20].

\section{Results and discussion}

\section{Molecular properties}

D. alaskensis FDH is a periplasmic enzyme which was purified and stored in aerobic conditions like FDHs from $D$. gigas and $D$. desulfuricans. The UV-vis absorption spectrum of $D$. alaskensis FDH is identical to that of the D. gigas FDH [4]. The spectrum exhibits a shoulder at $320 \mathrm{~nm}$ and a broad absorbance band around $400 \mathrm{~nm}$, as usually found in proteins having [4Fe-4S] clusters. Molecular mass determination showed a single symmetrical elution peak corresponding to a molecular mass of $126 \pm 2 \mathrm{kDa}$. Two bands with molecular weights of $93 \pm 3 \mathrm{kDa}$ and $32 \pm 2 \mathrm{kDa}$ were observed under denaturing conditions (SDS-PAGE). $D$. alaskensis FDH is a heterodimeric protein which contains two types of subunits $(\alpha, \beta)$. Plasma emission assay detected $0.4 \pm 0.1 \mathrm{Mo} /$ molecule, $0.3 \pm 0.1 \mathrm{~W} /$ molecule, and $6 \pm 1 \mathrm{Fe} /$ molecule. No heme $c$ was detected when specific gel staining was performed and no heme is visible on the UV-vis spectrum. Pterin nucleotide analysis identified $1.3 \pm 0.1$ guanine monophosphate derivative, which suggests a di-pterin coordination with the metal atom. The molecular properties evaluated for D. alaskensis FDH are similar to those of D. gigas FDH. This implies that the $\alpha$-subunit contains the pterin cofactor and one iron-sulfur cluster whereas the $\beta$-subunit contains the remaining three iron-sulfur clusters, as in the D. gigas enzyme [8].

D. alaskensis FDH is purified as two isoforms, each containing either molybdenum or tungsten. The two isoforms cannot be chromatographically separated, which suggests they have the same isoelectric point. The similar molecular properties evaluated for all the FDHs characterized in SRB indicate that they are closely related proteins, despite the different metal atom found at the pterin cofactor: Mo in $D$. desulfuricans, $\mathrm{W}$ in $D$. gigas, and both $\mathrm{W}$ and Mo in D. alaskensis.

\section{Growth conditions and enzymatic properties}

Preliminary studies of the effect of Mo and W concentrations upon the enzymatic activity of FDH produced by $D$. alaskensis have revealed that the addition of Mo, $\mathrm{W}$, and $\mathrm{Mo}+\mathrm{W}$ supplements did not influence the growth rate determined for the cultures. However, addition of $\mathrm{W}$ seems to induce a significant increase of biomass production when compared with cultures grown in the absence of metal supplements or in the presence of Mo. FDH activity assays on the abovementioned cultures revealed that addition of $\mathrm{W}$ (final concentration of $47 \mathrm{nM}$ ) resulted in significantly higher levels of FDH activity in the crude extract. This effect was not observed when $\mathrm{W}$ was added in combination with Mo, thus suggesting that, even though Mo and W can be used indiscriminately, there might be a competition process between the two metals. It seems plausible to speculate that there might be direct competition for the binding site for which Mo might have a higher affinity, even though it is catalytically less efficient than $\mathrm{W}$. This is in line with the results obtained for the Mo and $\mathrm{W}$ forms of DMSO reductase from $R$. capsulatus strain H123 [21]. Further studies are currently being conducted in order to clarify these preliminary data.

\section{EPR spectroscopy}

EPR spectra taken on the as-isolated enzyme (not shown) show the presence of one rhombic signal 
$\left(g_{1}=1.965, g_{2}=1.987, g_{3}=2.018\right)$ observable without significant broadening up to $120 \mathrm{~K}$. Spin quantification of the EPR signal in the as-isolated form of this signal yielded less than $0.1 \mathrm{spin} / \mathrm{molecule}$, which is compatible with $\mathrm{Mo}(\mathrm{V})$ and/or $\mathrm{W}(\mathrm{V})$ ions. EPR signals associated with $\mathrm{Mo}(\mathrm{V})$ and $\mathrm{W}(\mathrm{V})$ ions having $g_{\max }>2$ have been reported in a few Mo- and $\mathrm{W}$-containing proteins $[6,13$, 22]. These values may be associated with $\mathrm{Mo}(\mathrm{V})$ and/or $\mathrm{W}(\mathrm{V})$ ion sites coordinated by four thiolates from two pterin moieties and a Se-cysteine or a cysteine.

Figure 1 shows variable-temperature EPR spectra taken in the 5-40 K temperature range for $D$. alaskensis FDH samples when reduced with excess dithionite. Both the $g$-values and the low temperatures for observing these signals suggest that they arise from reduced ironsulfur clusters of the type $[4 \mathrm{Fe}-4 \mathrm{~S}]^{+}$. The spectrum in Fig. 1a, which is associated with the iron-sulfur cluster named $\mathrm{Fe} / \mathrm{S} \mathrm{I}$, appears at temperatures below $70 \mathrm{~K}$ and shows no significant broadening effects below $40 \mathrm{~K}$. The simulation of this signal yielded the EPR parameters given in Table 1. A second broader rhombic EPR signal overlapped with that of Fig. 1a appears around $25 \mathrm{~K}$ (Fig. 1b). Simulation of this signal was achieved by adding in the same ratio the simulations identified as $\mathrm{Fe} /$ $\mathrm{S} \mathrm{I}$ and $\mathrm{Fe} / \mathrm{S} \mathrm{II}$ in Fig. 1 (EPR parameters in Table 1). The spectra below $15 \mathrm{~K}$ (Fig. 1c) show additional broad features overlapped with the signals of centers $\mathrm{Fe} / \mathrm{S} \mathrm{I}$ and II and must arise from the remaining iron-sulfur centers. The spectrum resulting from the difference between Fig. 1c and Fig. 1b (not shown) shows characteristics similar to that of $\mathrm{Fe} / \mathrm{S}$ II, but broader. Spin quantification of the spectrum shown in Fig. 1c yielded

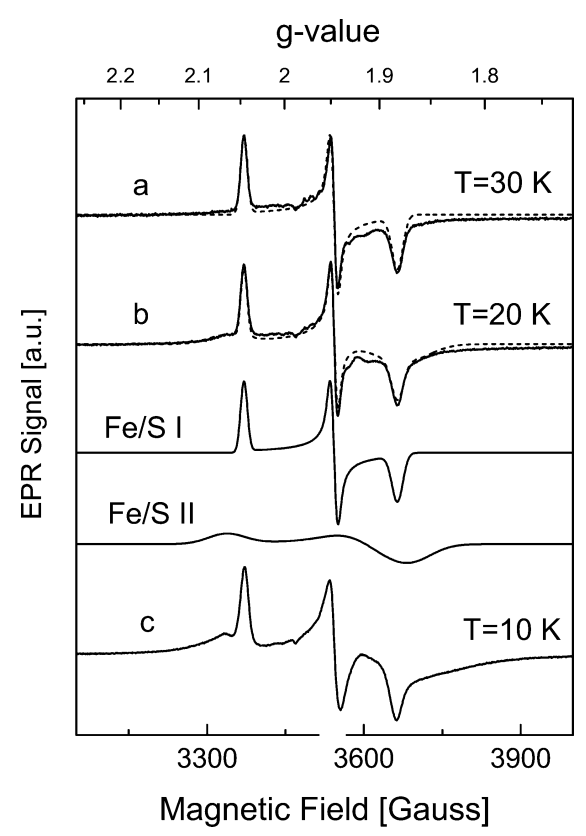

Fig. 1 Variable-temperature EPR spectra $(a, b$, and $c)$ taken of the dithionate-reduced state of $D$. alaskensis FDH. The signals $\mathrm{Fe} / \mathrm{SI}$ and $I I$ and dashed lines are simulations. The EPR parameters used in the spectral simulation are given in Table 1
Table 1 EPR parameters obtained by simulation in D. alaskensis FDH. Hyperfine parameters $(A)$ and linewidths (in parentheses) are given in gauss $(1 \mathrm{G}=0.1 \mathrm{mT})$; $g$-values $\pm 0.001, A$-values \pm 1

\begin{tabular}{lllllll}
\hline & $g_{1}$ & $g_{2}$ & $g_{3}$ & $A_{1}$ & $A_{2}$ & $A_{3}$ \\
\hline $\mathrm{Mo}$ & $1.959(8)$ & $1.968(8)$ & $1.971(8)$ & 14 & 16 & 16 \\
$\mathrm{~W}$ & $1.916(15)$ & $1.933(13)$ & $1.955(12)$ & & & \\
$\mathrm{Fe} / \mathrm{S} \mathrm{I}$ & $1.882(21)$ & $1.946(12)$ & $2.046(13)$ & & & \\
$\mathrm{Fe} / \mathrm{S} \mathrm{II}$ & $1.868(80)$ & $1.913(90)$ & $2.066(70)$ & & & \\
\hline
\end{tabular}

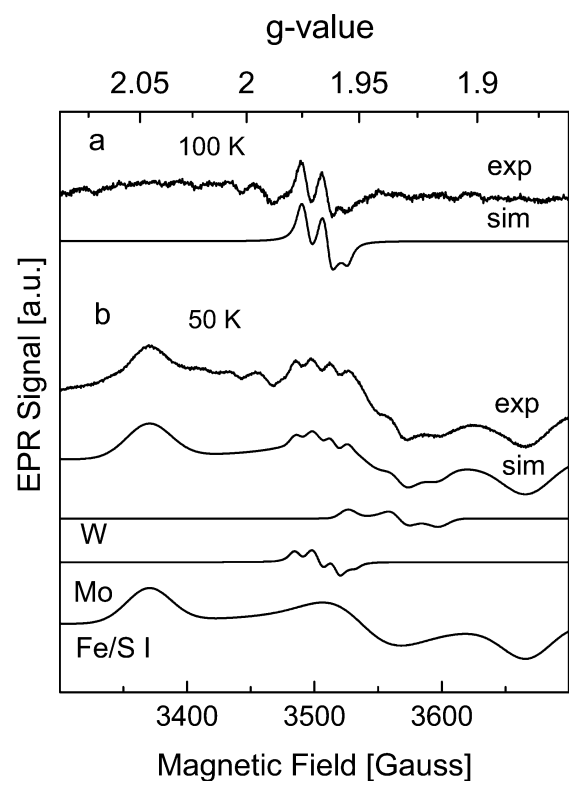

Fig. 2 EPR spectra taken of the dithionate-reduced state of $D$. alaskensis FDH in the 40-120 K temperature range, together with spectral simulation. Experimental conditions: microwave power, $2 \mathrm{~mW}(a)$ and $0.6 \mathrm{~mW}(b)$; modulation amplitude, $4 \mathrm{G}_{\mathrm{pp}}$; microwave frequency, $9.65 \mathrm{GHz}$

$0.24 \mathrm{spin} / \mathrm{Fe}$, which indicates that all the iron-sulfur clusters are completely reduced in the dithionite-reduced state. Spin quantification considering the protein concentration yielded a lower value (1.4 spin/molecule) than the expected one for a protein having $4 \times[4 \mathrm{Fe}-4 \mathrm{~S}]$ centers with all the iron-sulfur clusters in their reduced form. However, this was expected because of the low value found for the iron content $(6 \mathrm{Fe} /$ molecule), which indicates that the protein loses some iron as in the closely related $D$. gigas enzyme [8]. Other minor signals overlapping the $\mathrm{Fe} / \mathrm{S}$ signals, accounting for less than $0.1 \mathrm{spin} /$ protein associated with $\mathrm{Mo}(\mathrm{V})$ and $\mathrm{W}(\mathrm{V})$ species, were not considered for the simulation of the spectra in Fig. 1.

Figure 2 shows two spectra taken in the $40-120 \mathrm{~K}$ temperature range. The spectrum at $100 \mathrm{~K}$ shows an EPR signal which is observed between 100 and $120 \mathrm{~K}$ without changes. The lineshape of this signal resembles the so-called slow-type signal, which is associated with $\mathrm{Mo}(\mathrm{V})$ ions in several Mo-containing hydroxylases of the xanthine oxidase family $[1,3]$. Slow-type EPR signals present almost-axial symmetry with resonances split by a 
single proton. D. alaskensis FDH presents EPR parameters (Table 1) within the typical values found for $\mathrm{Mo}(\mathrm{V})$ species giving slow-type signals, and in particular they are identical to those found in the D. gigas AOR [23]. This suggests that the structural characteristics of the molybdenum site of $D$. alaskensis FDH are similar to the one found in D. gigas AOR [24].

The spectra below $70 \mathrm{~K}$ showed the emergent $\mathrm{Fe} / \mathrm{S} \mathrm{I}$ EPR signal described above together with another rhombic signal, with all the $g$-values lower than 2 (see Fig. 2b). This signal has larger deviations from the freeelectron $g$-value and larger linewidth compared to the ones associated with $\mathrm{Mo}(\mathrm{V})$ species, pointing to tungsten in a $d^{1}$ configuration. The lack of observation of the hyperfine interaction with the ${ }^{183} \mathrm{~W}$ nucleus $(I=1 / 2$, $14.4 \%$ natural abundance) may be due to the small intensity of this signal. However, this type of hyperfine splitting has not been observed in several other W proteins [2]. The broadening of the $\mathrm{W}(\mathrm{V})$ ion signal at $\sim 70 \mathrm{~K}$ is unusual for an ion in a $\mathrm{d}^{1}$ configuration and suggests that the $\mathrm{W}(\mathrm{V})$ ion is magnetically coupled to another faster relaxing paramagnet. EPR studies performed on model systems suggest a correlation between the $g_{\text {av }}$ value and the number of thiolate ligands in oxotungsten(V) species [25]. According to this correlation, the W center in D. alaskensis FDH $\left(g_{\text {av }}=1.934\right)$ should be bound to four thiolates.

The EPR parameters obtained for the tungsten site suggest a bis-dithiolene coordination, as observed in other Mo- and W-containing proteins of the DMSO reductase family [3]. On the other hand, EPR parameters obtained for $\mathrm{Mo}(\mathrm{V})$ ions indicate a metal site coordination similar to the one observed in D. gigas AOR, where just one pterin molecule is linked to the molybdenum atom. The pterin cofactor of the proteins belonging to the DMSO reductase family shows a coordination geometry that is highly flexible. Three structures have been reported for DMSO reductases, two from $R$. capsulatus [26, 27] and one from $R$. spheroides [28]. These structures showed that one of the pterin molecules can be partially or totally uncoordinated. Our EPR data suggest that the Mo site of $D$. alaskensis FDH is coordinated by only one pterin molecule. Therefore the Mo site in D. alaskensis FDH might have an analogous structure to the Mo AOR site from D. gigas, which would explain the striking similarity between the EPR spectra of both proteins.

Analysis of the magnetic interactions

As seen in Fig. 2, the resonance lines of the $\mathrm{Mo}(\mathrm{V})$ ion signal are split at low temperatures, which indicates that $\mathrm{Mo}(\mathrm{V})$ ions are magnetically coupled to another paramagnetic center. The $\mathrm{W}$ and Mo signals are typical of mononuclear $\mathrm{Mo}(\mathrm{W})$ atoms in a $\mathrm{d}^{1}$ configuration, which discards the possibility of a magnetic interaction between both metal ions. Therefore the splitting of the $\mathrm{Mo}(\mathrm{V})$ signal must arise from the iron-sulfur clusters.
Both dipolar and superexchange interactions have been suggested to be responsible for such couplings in metalloproteins. Dipolar couplings predict an anisotropic splitting that depends on the angle between the spin-spin distance and the external magnetic field, although a zero splitting at the principal $g$-values of the $\mathrm{Mo}(\mathrm{V})$ ion signal can be obtained at the "trimagic" angle [29]. In contrast, superexchange interactions between two anisotropic paramagnets predict an isotropic splitting with a magnitude of $J\left(H_{\mathrm{ex}}=J \boldsymbol{S}_{1} \boldsymbol{S}_{2}\right)$ when $|J|<|\Delta g \beta B|$, where $\Delta g$ is the difference between the effective $g$-values of both centers, $\beta$ is the Bohr magneton, and $B$ the external magnetic field. In the case we are considering where the resonances of one of the centers are split by hyperfine interactions with a species with nuclear spin $(I=1 / 2)$, it is straightforward to show that this condition is $|J|<|\Delta g \beta B \pm 1 / 2 A|$, where $A$ is the hyperfine parameter. Furthermore, magnetic interactions depend on temperature when one of the species of the interacting pair has a relaxation rate $\left(T_{1}\right)$ faster than the other one. This may produce an enhancement of the relaxation rate of the slowly relaxing paramagnetic center and/or a temperature dependence of the splitting of the resonance lines $[30,31,32,33]$.

Figure $3 \mathrm{~A}$ shows that the $\mathrm{Mo}(\mathrm{V})$ resonances are fully split at temperatures below $50 \mathrm{~K}$, partially collapsed in the $55-80 \mathrm{~K}$ range, and fully collapsed at $100 \mathrm{~K}$ (no linewidth changes were observed above $100 \mathrm{~K}$ and below $50 \mathrm{~K}$ ). The fully split spectra, for example the one shown in Fig. 2b, were accounted for by assuming an isotropic splitting of the $\mathrm{Mo}(\mathrm{V})$ resonances, which indicates that superexchange is the magnetic interaction operating between the interacting centers. Therefore, the

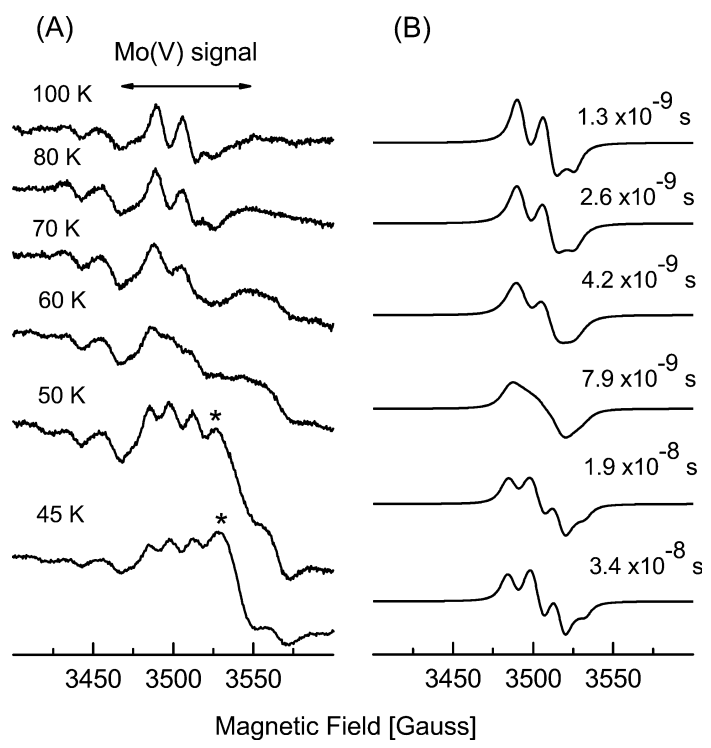

Fig. 3 A Temperature variation of the slow-type EPR signal for the dithionate-reduced state of $D$. alaskensis FDH. The peaks marked with an asterisk come from other paramagnetic species. B Spectral simulation as a function of the relaxation time $\left(T_{1}\right)$ of $\mathrm{Fe} / \mathrm{S}$ I. The EPR parameters used in the spectral simulation are given in the text 
temperature variation of the spectra associated with $\mathrm{Mo}(\mathrm{V})$ ions (Fig. 3) were simulated by assuming a dimeric model composed of two interacting $S=1 / 2$ centers relaxing independently [20], including in addition the hyperfine coupling with a nucleus of nuclear spin $I=1 / 2$ at one of the centers, both centers being magnetically coupled only by exchange interaction (Fig. 3). The powder-like spectra were computed after obtaining the absorption spectrum of this system with parameters representing all the interactions, allowing for these to vary according to the dimer orientation with reference to the external magnetic field. In this model the relaxation times $T_{2}$ contribute only to the linewidth of the individual resonances of each paramagnetic center. A good agreement between experimental and simulated spectra was obtained using the relaxation times evaluated for $\mathrm{Fe} / \mathrm{S} \mathrm{I}$ (see below), the $g$-values for the $\mathrm{Mo}(\mathrm{V})$ ion given in Table 1, and an exchange parameter $J=1.2 \times 10^{-3} \mathrm{~cm}^{-1}$.

Figure 4 shows the temperature variation of the $T_{1}$ values associated with the $\mathrm{Fe} / \mathrm{S}$ I center. The $T_{1}$ values were evaluated following a method described elsewhere [34], which is applicable when the unbroadened spectrum shows at least one relatively well-defined peak of nearly gaussian shape, as is the case of the $g_{1}$ and $g_{3}$ resonances of the $\mathrm{Fe} / \mathrm{S}$ I center. The difference between the relaxation times evaluated from both peaks varies by less than $6 \%$ and therefore the mean value was utilized to obtain Fig. 4. These data were least-squares fitted assuming an Orbach mechanism $\left[1 / T_{1} \propto \exp (-\Delta /\right.$ $k T$ ) for $\Delta>>k T$ ], where $k$ is Boltzmann's constant and $\Delta=184 \pm 12 \mathrm{~cm}^{-1}$ is the energy of an excited electronic state [35]. This value is within the magnitude order reported for iron-sulfur clusters of the $[4 \mathrm{Fe}-4 \mathrm{~S}]$ type [36].

The good agreement obtained between the experimental and simulated spectra indicates that the iron-

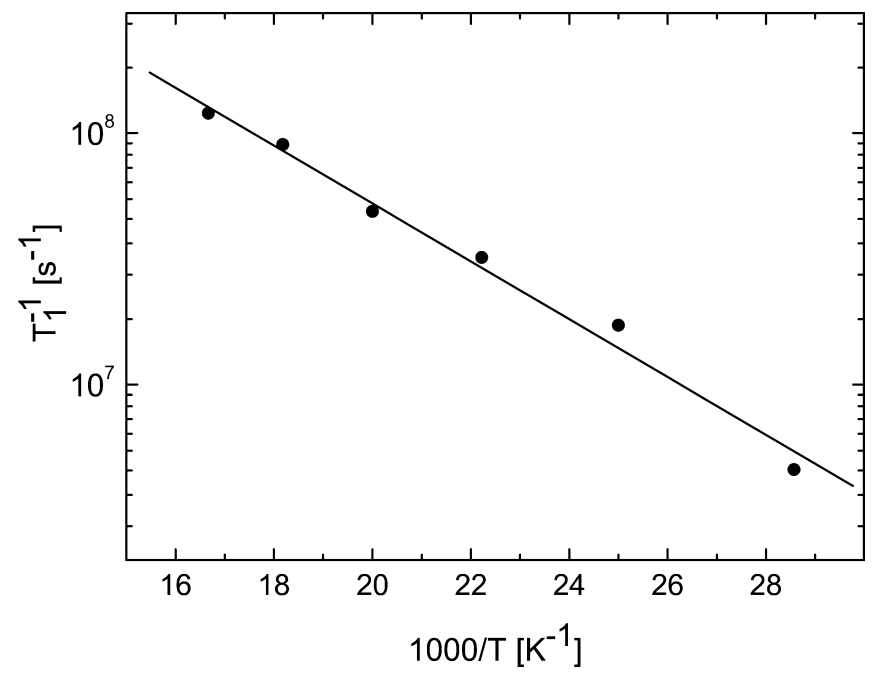

Fig. 4 Temperature dependence of the spin-lattice relaxation time for $\mathrm{Fe} / \mathrm{S} \mathrm{I}$ in $D$. alaskensis $\mathrm{FDH}$. The data were least-squares fitted assuming an Orbach mechanism $\left[1 / T_{1} \propto \exp (-\Delta / k T)\right.$ for $\left.\Delta>>k T\right]$; $\Delta=184 \pm 12 \mathrm{~cm}^{-1}$ sulfur center identified as $\mathrm{Fe} / \mathrm{S} \mathrm{I}$ is the center that interacts magnetically with the molybdenum center and therefore is situated in the $\alpha$-subunit of the protein. This suggests the existence of a suitably oriented chemical path connecting both centers. Although no splitting was detected at the $\mathrm{W}$ signal, this signal is not detectable above $70 \mathrm{~K}$, which reveals an unusual relaxation behavior for the $\mathrm{W}(\mathrm{V})$ ions. This suggests that $\mathrm{W}(\mathrm{V})$ species are also likely to be magnetically coupled to the $\mathrm{Fe} / \mathrm{S}$ I center. The relaxation times $T_{1}$ of the remaining $\mathrm{Fe} / \mathrm{S}$ centers could not be evaluated because of the superposition of the spectra. However, the fact that these centers are not detected at temperatures above $30 \mathrm{~K}$ indicates that the associated $T_{1}$ are even lower than that of $\mathrm{Fe} / \mathrm{S} \mathrm{I}$, and therefore unable of producing the changes observed at the $\mathrm{Mo}(\mathrm{V})$ ion signal.

\section{Conclusions}

The main goals of the present study can be focused on two aspects: the simultaneous detection of Mo and W and the assignment of the iron-sulfur center proximal to the pterin cofactor. The former constitutes one of the few examples of an enzyme of the vast members of the molybdo- and tungstoenzymes that can incorporate both metal atoms. The latter utilizes EPR together with a semiempirical model to analyze the magnetic interactions between paramagnetic centers. This model was demonstrated to be very useful to gain insight into the structural aspects of metalloproteins having exchangecoupled paramagnetic centers.

Acknowledgements This work was supported by Fundação para a Ciência e Tecnologia (Portugal) POCTI/BME/36152/99 and CAI + D-UNL (Argentina). MJF thanks the British Council for financial support for travel to Portugal.

\section{References}

1. Hille R (1996) Chem Rev 96:2757-2816

2. Johnson MK, Rees DC, Adams MWW (1996) Chem Rev 96:2817-2839

3. Romão MJ, Knäblein J, Huber R, Moura JJG (1997) Prog Biophys Mol Biol 68:121-144

4. Almendra MJ, Brondino CD, Gavel O, Pereira AS, Tavares P, Bursakov S, Duarte R, Caldeira J, Moura JJG, Moura I (1999) Biochemistry 38:16366-16372

5. de Bok FAM, Hagedoorn PL, Silva PJ, Hagen WR, Schiltz E, Fritsche K, Stams E, Fritsche K, Stams AJM (2003) Eur J Biochem 270:2476-2485

6. Costa C, Teixeira M, LeGall J, Moura JJG, Moura I (1997) J Biol Inorg Chem 2:198-208

7. George GN, Costa C, Moura JJG, Moura I (1999) J Am Chem Soc 121:2625-2626

8. Raaijmakers H, Teixeira S, Dias JM, Almendra MJ, Brondino CD, Moura I, Moura JJG, Romão MJ (2001) J Biol Inorg Chem 6:398-404

9. Raaijmakers H, Macieira S, Dias JM, Teixeira S, Bursakov S, Huber R, Moura JJ, Moura I, Romao MJ (2002) Structure 10:1261-1272 
10. Dias JM, Than ME, Humm A, Huber R, Bourenkov GP, Bartunik HD, Bursakov S, Calvete J, Caldeira J, Carneiro C, Moura JJG, Moura I, Romão MJ (1999) Structure 7:65-77

11. Boyington JC, Gladyshev VN, Khangulov SV, Stadtman TC, Sun PD (1997) Science 275:1305-1308

12. Bursakov SA, Liu MY, Payne WJ, LeGall J, Moura I, Moura JJG (1995) Anaerobe 1:55-60

13. Khangulov SV, Gladyshev VN, Dismukes GC, Stadtman TC (1998) Biochemistry 37:3518-3528

14. Feio MJ (2000) PhD thesis. University of Portsmouth, UK

15. Postgate JR, Kent HM, Robson RL, Chesshyre JA (1984) J Gen Microbiol 130:1597-1601

16. Lowry OH, Rosenbrough NJ, Farr AL, Randall RJ (1951) J Biol Chem 193:265-273

17. Gremer L, Meyer O (1996) Eur J Biochem 238:862-866

18. Frunzke K, Heiss B, Meyer O, Zumft WG (1993) FEMS Microbiol Lett 113:241-246

19. Atherton MM (1973) Electron spin resonance: theory and applications. Wiley, New York

20. Salikhov KM, Galeev RT, Voronkova VK, Yablokov YV, Legendziewicz J (1997) Appl Magn Reson 14:457-472

21. Stewart LJ, Bailey S, Bennet B, Charnock JM, Garner CD, McAlpine AS (2000) J Mol Biol 299:593-600

22. Deaton JC, Solomon EI, Watt GD, Wetherbee PJ, Durfor CN (1987) Biochem Biophys Res Commun 149:424-430

23. Turner N, Barata B, Bray RC, Deistung J, Le Gall J (1987) Biochem J 243:755-761
24. Romão MJ, Archer M, Moura I, Moura JJG, LeGall J, Engh R, Schneider M, Hof P, Huber R (1995) Science 167:1170-1176

25. Barnard KR, Gable RW, Wedd AG (1997) J Biol Inorg Chem 2:623-633

26. McAlpine AS, McEwan AG, Bailey S. (1998) J Mol Biol 275:613-623

27. Schneider F, Löwe J, Huber R, Schindelin H, Kisker C, Knäblein J (1996) J Mol Biol 263:53-69

28. Schindelin H, Kisker C, Hilton J, Rajagopalan KV, Rees DC (1996) Science 272:1615-1621

29. Abragam A (1961) The principles of nuclear magnetism. Oxford Univesity Press, Oxford

30. Hirchs DJ, Beck WF, Innes JB, Brudvig GW (1992) Biochemistry 31:532-541

31. Hirchs DJ, Beck WF, Lynch JB, Que L Jr, Brudvig GW (1992) J Am Chem Soc 114:7475-7481

32. Andrade SLA, Brondino CD, Feio MJ, Moura I, Moura JJG (2000) Eur J Biochem 267:2054-2061

33. Caldeira J, Belle V, Asso M, Guigliarelli B, Moura I, Moura JJG, Bertrand P (2000) Biochemistry 39:2700-2707

34. Bertrand P, Roger G, Gayda JP (1980) J Magn Reson 40:539549

35. Pilbrow JR (1990) Transition ion electron paramagnetic resonance. Clarendon Press, Oxford

36. Gayda JP, Bertrand P, More C, Le Gall J, Cammack RC (1981) Biochem Biophys Res Commun 99:1265-1270 